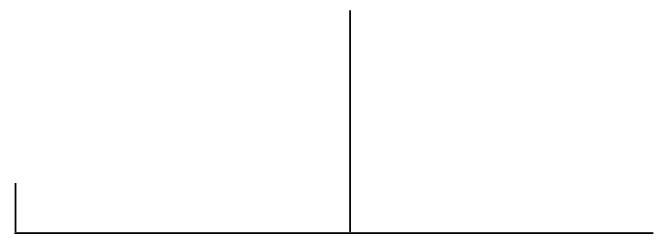

Rev. Latinoam. Psicopat. Fund., São Paulo, v. 13, n. 4, p. 652-666, dezembro 2010

\title{
Desafio aos requisitos pré-médicos tradicionais como indicadores de sucesso na Escola de Medicina: o Programa Humanidades e Medicina da Escola de Medicina Monte Sinai*
}

\section{Objetivo}

Estudantes competem agressivamente enquanto se preparam para o MCAT (Teste de Admissão à Universidade de Medicina, na sigla em inglês) e atendem às exigências pré-médicas tradicionais** que possuem valor educacional incerto para carreiras médicas e científi-

* Publicado originalmente em Academic Medicine, v. 85, n. 8, p. 1378-1383, August 2010. Tradução de Luana Villac.

** Nos Estados Unidos a medicina só pode ser estudada em nível de pós-graduação. Os candidatos à escola médica devem antes completar uma graduação no ensino superior em outra área de estudo à sua escolha. Tradicionalmente, os estudantes optam por graduar-se em cursos focados em ciências exatas e biológicas, seguindo o chamado caminho pré-médico. O MCAT é o teste padrão realizado pelos alunos durante a graduação para a admissão nas faculdades de medicina. (N. da T.) 
cas e limitam seu escopo nas artes liberais e na educação biomédica. O presente estudo avaliou o desempenho nas faculdades de medicina de alunos graduados em ciências humanas e sociais os quais não frequentaram disciplinas de química orgânica, física e cálculo, isto é, não seguiram o caminho pré-médico, e não prestaram o MCAT.

\section{Método}

Os autores compararam e puseram em contraste os resultados acadêmicos de 85 alunos do Programa de Medicina e Humanidades (HuMed) da Faculdade de Medicina Monte Sinai, em Nova Iorque, com os de 606 estudantes que se prepararam para ingressar no curso de medicina de forma tradicional, das turmas de graduação 2004-2009. Os autores analisaram conhecimento científico básico, desempenho no estágio, humanismo, liderança, serviços comunitários, participação em pesquisas, distinções e honras.

Não houve entre os grupos diferenças estatisticamente significativas em distinção no estágio, a não ser em psiquiatria (alunos do HuMed superaram seus colegas, $\mathrm{P}<$. 0001), e em distinção na colação de grau. Embora a probabilidade de alunos do HuMed de manter-se em um projeto orientado com duração de um ano $(\mathrm{P}=.001)$ ter sido significativamente maior, não houve diferença em distinção em pesquisa $(\mathrm{P}=.281)$. Os alunos do HuMed tiveram maior probabilidade de obter notas mais baixas no United States Medical Licensing Examination Step 1 $(221 \pm 20$ versus $227 \pm 19, \mathrm{P}=.0039)$ e de efetuar o trancamento da matrícula por razões não escolares $(\mathrm{P}=.0001)$. Houve uma tendência maior entre os alunos do HuMed para residências em cuidados primários e psiquiatria e menor em subespecialidades cirúrgicas e anestesiologia.

\section{Conclusões}

Alunos sem a tradicional preparação pré-medica obtiveram desempenho equivalente ao dos colegas que seguiram a preparação tradicional. 


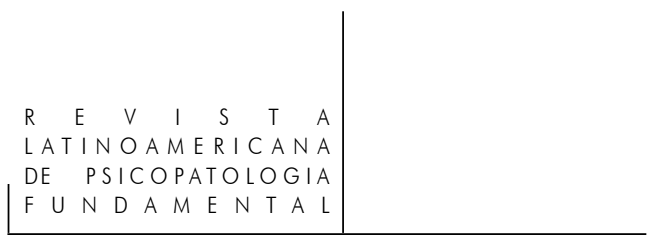

A American Medical Association (Associação Médica Americana) iniciou seus esforços para estandardizar a educação médica na segunda metade do século XIX. Em 1904, ela criou o Council on Medical Education (Conselho de Educação em Medicina) e pouco depois realizou com a Carnegie Foundation (Fundação Carnegie) uma avaliação de todas as escolas de medicina dos Estados Unidos. ${ }^{1 *}$ O homem que liderou esse levantamento, Abraham Flexner, ${ }^{2}$ incluiu entre suas recomendações para a admissão em faculdades de medicina as exigências pré-médicas. Em 1930 as exigências científicas pré-médicas estavam claramente estabelecidas: dois semestres cada de química, física e biologia gerais e um semestre de química orgânica. Apesar da antiga e contínua oposição a esses requisitos estreitos, oitenta anos depois eles permanecem essencialmente inalterados. ${ }^{3}$

A mais séria e abrangente oposição iniciou-se em 1981. A Association of American Medical Colleges (Associação de Universidades Norte-Americanas de Medicina) criou o grupo Educação Profissional Geral do Médico e Preparação para a Universidade de Medicina (GPEP, na sigla em inglês), reunindo diretores de universidades, reitores, membros de departamento, professores de disciplinas humanas, exatas e biológicas e médicos em atividade, com o objetivo de analisar as políticas prevalentes de educação em medicina e a pertinência da preparação pré-medica.

O relatório resultante, de 1984 - Médicos para o século $X X I^{4}$ - recomendava a abertura da preparação para as escolas de medicina e a modificação das exigências para admissão nas mesmas. De acordo com o GPEP, a tendência prematura dos estudantes universitários a moldar sua educação de acordo com o objetivo estreito de admissão na faculdade de medicina resultava em uma experiência universitária desequilibrada que excluía a possibilidade de uma educação ampla em artes liberais. O GPEP foi o primeiro grupo a reconhecer formalmente a existência desta "síndrome pré-médica" e previu que essa tendência viria a ser reforçada caso as políticas de admissão em faculdades de medicina continuassem a enfatizar altas notas no MCAT e histórico escolar excepcional. $\mathrm{O}$ GPEP argumentou que médicos não podem limitar-se à aquisição e sustentação de conhecimento, expertise e habilidade clínica, mas devem também aplicar e lapidar valores humanísticos e atitudes comuns a profissionais dedicados ao cuidado e à cura.

* Apesar de diferente das normas desta revista, as notas foram mantidas de acordo com o original inglês. (N. do E.)

Rev. Latinoam. Psicopat. Fund., São Paulo, v. 13, n. 4, p. 652-666, dezembro 2010 
A oposição às exigências pré-médicas tradicionais permanece sendo articulada por uma série de líderes do campo da educação em medicina. ${ }^{5,8}$ De acordo com Gross e colegas, ${ }^{9}$ os críticos das exigências pré-medicas pertencem a três categorias: aqueles que eliminariam quaisquer exigências, ${ }^{10}$ os que advogam a atualização contínua do currículo científico pré-médico ${ }^{5,7}$ e aqueles que acreditam que o currículo pré-médico deva ser ampliado de forma a refletir uma educação mais rica em artes liberais., ${ }^{5,6,8}$

Apesar da concordância generalizada de que muitas das exigências prémédicas possuem limitado valor educacional para o médico ou cientista em atividade e que uma educação mais ampla em artes liberais oferece benefícios diretos para os médicos e para seus pacientes, pouco progresso tem sido feito em direção a uma fundamental reavaliação. Em 2009, mais de $80 \%$ dos alunos matriculados em escolas médicas que entraram na universidade não cursaram ciências sociais ou humanas. ${ }^{9}$ A crença de que uma formação científica (incluindo um ano de química orgânica, física e cálculo) é a melhor maneira de preparar-se para a faculdade de medicina persiste e a dependência dos comitês de admissão de notas excepcionais no MCAT prevalece.

Embora líderes da educação em medicina tenham reconhecido que as recomendações do GPEP são interessantes, ao que sabemos nenhuma pesquisa definitiva foi realizada para avaliar a qualidade do desempenho dos alunos caso eles sejam admitidos nas faculdades de medicina com uma educação ampla em artes liberais em vez de terem preenchido os requisitos pré-médicos tradicionais.

Há mais de vinte anos, a Faculdade de Medicina Monte Sinai, em Nova Iorque, tem recebido alunos graduados em ciências sociais e humanas que especificamente não seguiram certas exigências pré-médicas padrão e não prestaram o MCAT. ${ }^{12}$ Um estudo de observação retrospectivo representativo de seis anos é aqui apresentado, comparando o desempenho acadêmico de estudantes que se graduaram em ciências humanas e sociais com os de alunos que seguiram uma educação pré-médica tradicional, a fim de determinar se as exigências pré-médicas são determinantes de sucesso na faculdade de medicina.

\section{O Programa de Medicina e Humanidades da Monte Sinai}

O Programa de Medicina e Humanidades da Monte Sinai foi criado na Faculdade de Medicina Monte Sinai em 1987. Ele oferece a alunos qualificados do antepenúltimo e penúltimo anos que estejam graduando-se em ciências humanas ou sociais admissão garantida à nossa faculdade de medicina mediante a obtenção do diploma. Os critérios de admissão baseiam-se nos históricos escolares do 


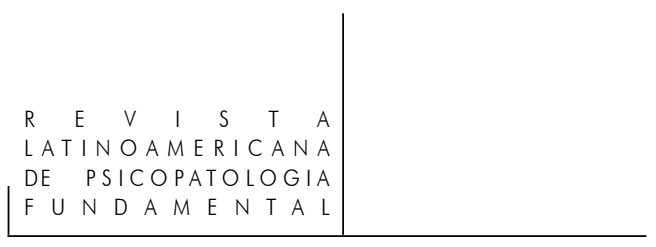

ensino médio e da faculdade, em duas redações individuais, três cartas de recomendação, pontuação no SAT (mínimo de 650 sobre 800 em humanas ou ACT equivalente) $*$ e duas entrevistas na Monte Sinai.

Uma vez aceitos, os alunos precisam manter um GPA (nota média) mínimo de 3,5 sobre quatro. Eles abstêm-se de química orgânica, física, cálculo e do MCAT, mas precisam obter no mínimo B em biologia e química geral (dois semestres cada).

Após completar o penúltimo ano, os alunos são solicitados a participar de um curso de verão com duração de oito semanas na Monte Sinai. A experiência inclui rotações de serviço clínico em todas as especialidades, seminários em tópicos médicos - tais como bioética, políticas de saúde, cuidados paliativos -, bem como um curso breve sobre "Princípios da Química Orgânica e Física Relacionados à Medicina" (seis horas de crédito para química orgânica, duas horas de crédito para física). Este curso cobre princípios básicos e cumpre a exigência de que todos os graduandos das faculdades de medicina licenciadas pela University of the State of New York devam ter créditos nessas disciplinas antes de receber o diploma médico. Os alunos passam por provas semanais cujos conceitos seguem o sistema aprovado/reprovado.

Ao concluir sua graduação, os estudantes aceitos no programa são encorajados a tirar um ano sabático antes de matricular-se.

Durante as férias de verão anteriores à matrícula, os alunos podem entrar para o opcional Programa de Aprimoramento de Verão (SEP, na sigla em inglês), que procura aclimatar os alunos recém-chegados ao HuMed junto ao currículo escolar médico e ao ambiente da faculdade. Aproximadamente $75 \%$ dos alunos matriculados no HuMed participam do SEP todos os anos. A grade curricular do programa inclui noções de bioquímica, anatomia, embriologia, fisiologia celular e histologia. As provas são autoavaliações revisadas em classe e os alunos não recebem notas.

\section{Método}

Foram examinados dados relativos aos resultados acadêmicos das turmas de graduação 2004-2009. Esse período foi escolhido devido ao aumento gradativo

* Similar ao Enem, O STA (Teste de Aptidão Escolar, na sigla em inglês) é o exame nacional norte-americano utilizado pela maioria das universidades como critério para a admissão de estudantes. O ACT é um exame equivalente requerido por certas universidades. (N. da T.) 
da proporção de alunos do HuMed matriculados a partir de 2004. Ademais, em 2004 foi apresentada uma ampla grade validada de Avaliação de Desempenho para Estudantes de Medicina (MSPE, na sigla em inglês) que identifica e quantifica todos os aspectos da atuação dos alunos. ${ }^{13}$ Utilizando as grades de MSPE dos estudantes, comparamos dados acadêmicos que refletem conhecimento científico básico, desempenho clínico, liderança e serviços comunitários, humanismo e profissionalismo, pesquisas/bolsas e residência de escolha.

No total, foram examinados resultados acadêmicos de 691 alunos graduados nas turmas de 2004-2009. Entre estes, 85 (12,3\%) vinham do HuMed. A proporção de alunos do HuMed em cada classe vai de 8,3\% (9/108), na turma de 2004 , a $16,4 \%$ (20/122), na turma de 2009. Na análise de especialização e distinção em pesquisa foram incluídos os membros da turma de 2010 que iniciaram seu ano escolar em 2009.

A aprovação IRB* não foi requisitada, uma vez que o presente estudo se inscreve sob isenção geral para dados sobre resultados educacionais pelo nosso conselho de revisão institucional.

\section{Monitorando grupos}

Como os alunos podem apresentar seu pedido de admissão no segundo ou penúltimo ano de graduação, podem tirar um ano sabático antes de matricular-se e podem acrescentar um quinto ano escolar ao curso de medicina, é impossível acompanhar um grupo intacto desde o pedido de admissão e a matrícula até o início do ano letivo. Por exemplo, aproximadamente $25 \%$ dos alunos de cada turma da Faculdade de Medicina Monte Sinai passam um ano escolar fazendo pesquisa, formando-se em uma turma diferente da inicial.

\section{Análise estatística}

Conduzimos tabulações cruzadas e ANOVA comparando os alunos do HuMed com os alunos de cursos pré-médicos através de diversas variáveis de banco de dados. Toda significância foi testada para um nível de confiança de $95 \%$. A análise dos dados foi gerada utilizando o software SAS (Versão 9.1, SAS System for Windows, 2002-2003, SAS Institute Inc., Cary, Carolina do Norte).

* O IRB (Institutional Review Board) é um comitê designado para aprovar, monitorar e avaliar pesquisas da área biomédica envolvendo sujeitos humanos. (N. da T.)

Rev. Latinoam. Psicopat. Fund., São Paulo, v. 13, n. 4, p. 652-666, dezembro 2010 


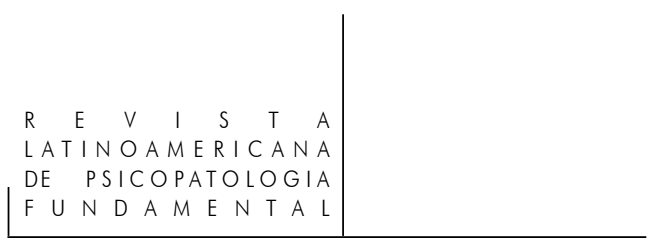

\section{Resultados}

Para avaliar o desempenho acadêmico na faculdade de medicina, foram comparados os dados dos 691 alunos que se graduaram nas turmas de 2004-2009. Não foram encontradas diferenças significativas entre os 85 alunos do HuMed e os 606 alunos que não se formaram pelo HuMed no que se refere aos resultados acadêmicos listados abaixo (tabela 1):

- Reprovação no United States Medical Licensing Examination (USMLE) Step 1.

- Desempenho excepcional no teste Comprehensive Clinical Assessment (COMPASS II) ao final do terceiro ano.

- Aprovação com distinção nos estágios (exceto psiquiatria, em que um número significativamente maior de alunos do HuMed recebeu aprovação com distinção).

- Pontos para liderança escolar no MSPE.

- Premiação da Gold Humanism Honor Society.

- Colocação entre os $25 \%$ melhores alunos da turma.

- Notas finais excepcionais ou excelentes no MSPE.

- Designação para a sociedade médica Alpha Omega Alpha.

Foram identificadas diferenças estatisticamente significativas nos seguintes resultados:

- Alunos do HuMed obtiveram notas mais baixas no USML Step 1.

- Alunos do HuMed obtiveram mais pontos por serviços comunitários no MSPE.

- Alunos do HuMed tiveram maior probabilidade de efetuar trancamento de matrícula por razões acadêmicas ou pessoais.

Foram analisados dados referentes à pesquisa e a projetos universitários para esse mesmo grupo e identificadas as seguintes diferenças entre os alunos do HuMed e os alunos advindos de outras graduações:

- Alunos do HuMed tiveram probabilidade significativamente maior que os demais alunos de dedicar um ano à pesquisa universitária $(28,2 \%$ ou $24 / 85$ versus $14,1 \%$ ou $86 / 606, \mathrm{P}=.001)$ e de receber a bolsa Doris Duke Clinical Research Fellowship $(10,6 \%$ ou $9 / 85$ versus $3 \%$ ou $18 / 606, \mathrm{P}=.001)$

- Alunos do HuMed tiveram maior probabilidade que os demais alunos $(11,8 \%$ ou $10 / 85$ versus $8,3 \%$ ou $50 / 606, \mathrm{P}=.281$ ) de graduar-se com distinção em pesquisa (assinando como primeiro autor em publicação submetida à avaliação por pares), mas a tendência não era significativa.

Ao avaliar escolhas de residência, foi identificada uma tendência maior entre os alunos do HuMed em relação aos demais alunos para o cuidado primário $(49,4 \%$ ou $42 / 85$ versus $39 \%$ ou $237 / 606)$ e para psiquiatria ( $14 \%$ ou $12 / 85$ versus 
$5,6 \%$ ou $34 / 606)$, e menor para subespecialidades cirúrgicas ( $7 \%$ ou $6 / 85$ versus $13 \%$ ou $80 / 606)$ e para anestesiologia $(5,8 \%$ ou $5 / 85$ versus $9 \%$ ou $55 / 606)$ (Figura 1). Houve uma tentativa de comparar a qualidade dos programas de residência alcançada por alunos nos dois grupos, mas a tarefa mostrou-se impossível. Com raras exceções, os graduandos da Monte Sinai optam por hospitais situados em centros de saúde universitários ou que possuem parcerias muito próximas com estes, o que torna muito difícil definir e comparar a qualidade das residências.

\section{TABELA 1}

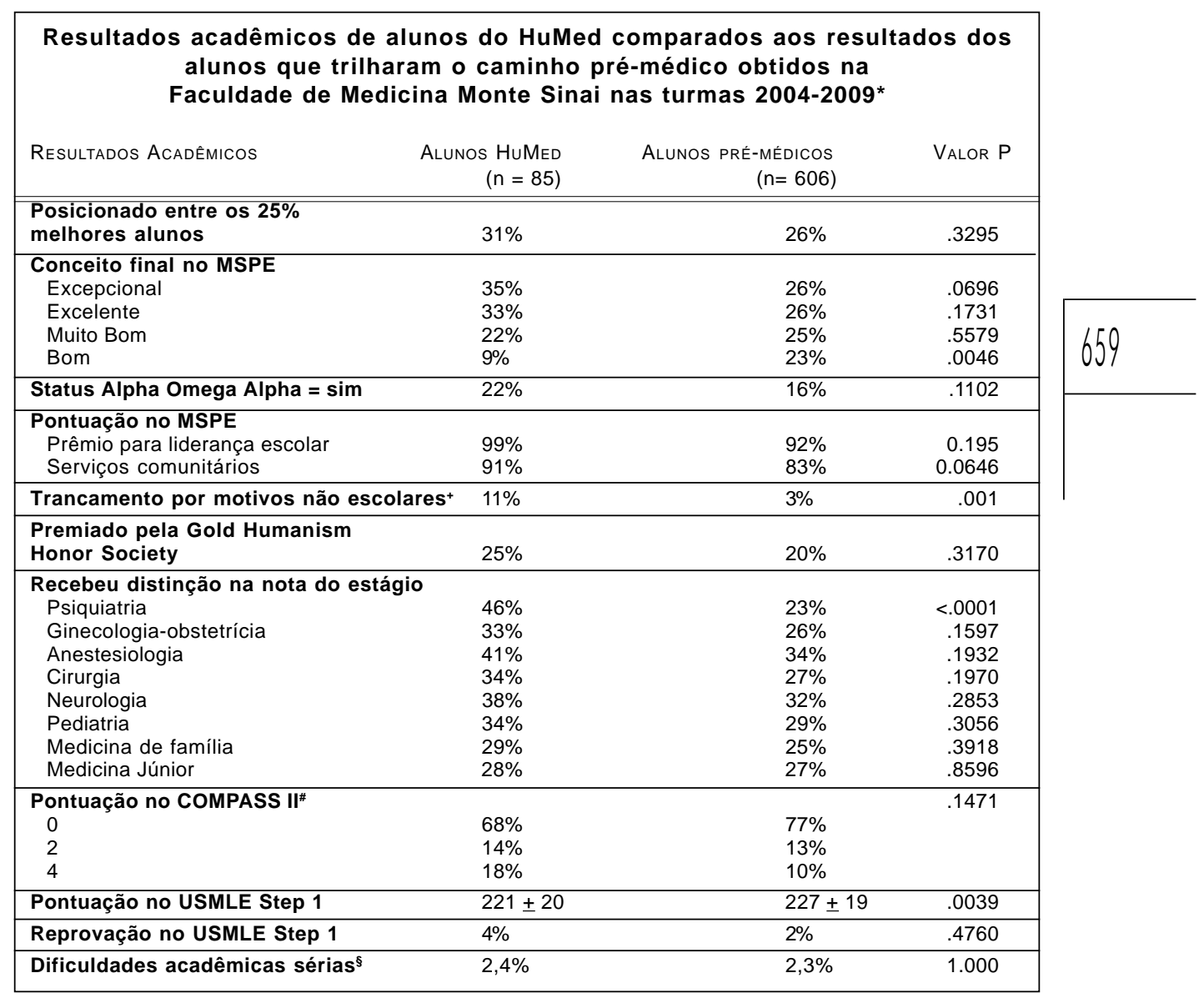

* Alunos pré-médicos atendem às exigências clássicas pré-médicas previamente à Faculdade de Medicina; os alunos do HuMed são graduados em ciências humanas e sociais e não as 
seguem. MSPE corresponde a Medical Student Performance Evaluation; USMLE, a United States Medical Licensing Examination.

+ Trancamentos não escolares correspondem a um nível de ausência relacionado a dificuldades acadêmicas, pessoais ou psiquiátricas.

\# COMPASS II é um exame clínico padrão, que tem o paciente como base, aplicado ao final do terceiro ano da faculdade de medicina.

$\S$ Dificuldades acadêmicas sérias correspondem a alunos com reprovação em três disciplinas diferentes ou duas reprovações e duas notas finais baixas durante o primeiro ou segundo ano da faculdade de medicina.
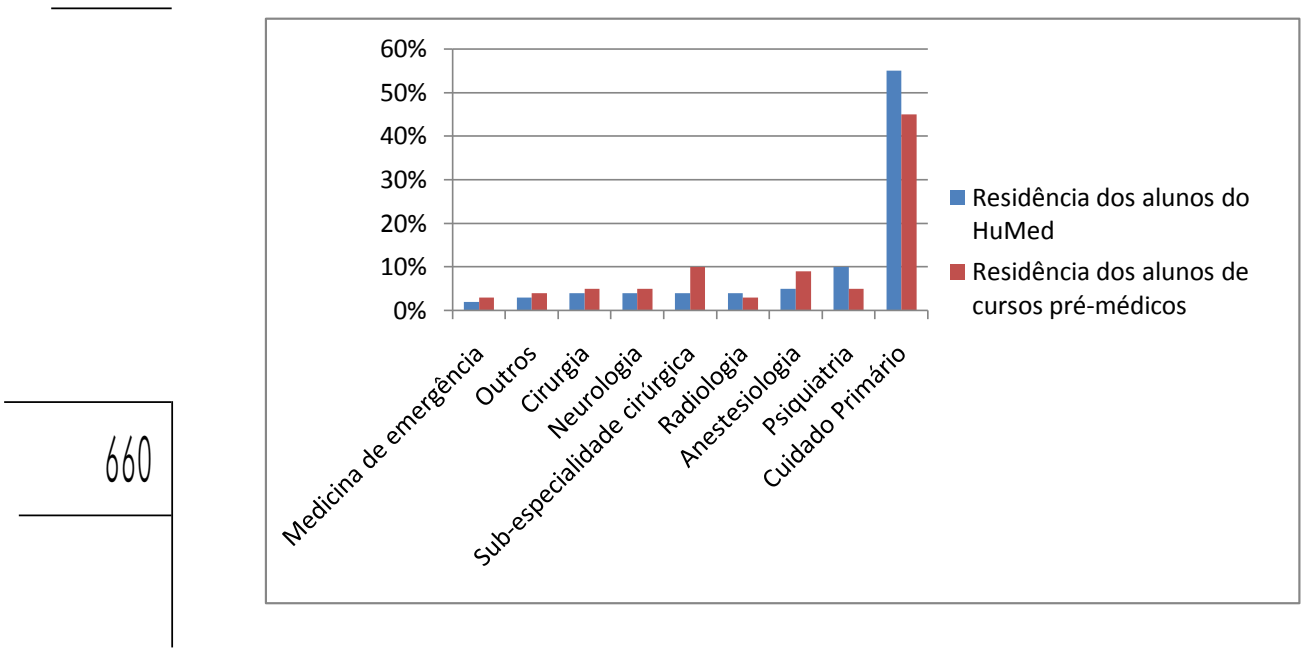

Figura 1

Distribuição da especialidade de residência entre os alunos da Monte Sinai nas turmas 2003-2009 durante o período de estudo. Dentre os 691 alunos, 85 vinham do programa HuMed e 606 vinham de cursos pré-médicos. Cuidado Primário inclui clínica médica, medicina de família, pediatria, ginecologia-obstetrícia e pediatria

\section{Discussão}

Ao longo do século XX, educadores e líderes da área médica vêm lamentando que as exigências pré-médicas tenham se distanciado de seus propósitos pretendidos: proporcionar a médicos aspirantes uma educação abrangente capaz de melhor prepará-los para tornarem-se pensadores independentes e criativos. ${ }^{6,8}$ Lewis Thomas, ${ }^{10}$ durante os anos 1970 , talvez tenha sido a voz mais radical: 
Tenho uma sugestão cuja implementação requer o seguinte anúncio dos reitores de todas as faculdades de medicina: daqui em diante, qualquer candidato à matrícula que se autorrotule como "pré-médico", distinguível de seus colegas por sua seleção de cursos, terá seu dossiê colocado em terceiro lugar em uma pilha de três. Fazer parte de qualquer "sociedade pré-médica" será por si só, razão para rejeição. Qualquer universidade que possua algo chamado "currículo pré-médico", ou que mantenha em suas facilidades escritórios para pessoas denominadas "conselheiros pré-médicos", será excluída de reconhecimento pelas faculdades de medicina.

Os pré-requisitos padrão para a admissão na faculdade de medicina constituem um grande investimento de horas de créditos e geralmente envolvem grandes assembleias de estudantes passivamente recebendo instrução didática. Além disso, a aguda consciência dos alunos da natureza competitiva do processo de admissão e da necessidade de pontuações excelentes na média científica e no MCTA induzem-nos a se matar por notas sem apreciar a ciência sendo estudada, e sua retenção da informação é apenas passageira. Os educadores transformaram "o que deveria ser uma meritocracia abrangente em uma 'testocracia' tacanha e estreita". ${ }^{14}$

Acreditamos que esse foco estreito promove outros resultados negativos. Primeiramente, o cultivo da verdadeira curiosidade científica diminui, uma vez que a satisfação pela descoberta científica se perde. Em segundo lugar, o processo de avaliação do desempenho dos alunos através de provas "objetivas" que validam o amplamente memorizado conhecimento atual nega o fato de que a ciência não é estática. Em terceiro lugar, a ciência deixa de ser apresentada como o portal de entrada através do qual as maravilhas da biomedicina podem ser iniciadas; na realidade, ela é distorcida em uma série de obstáculos a serem superados e funciona exclusivamente como um mecanismo filtrador (depuração, ${ }^{6,7}$ separação do joio e do trigo ${ }^{9}$ ) através do qual as comissões de admissão às faculdades de medicina selecionam os alunos.

Nossos dados, coletados durante seis anos, confirmam descobertas anteriores sobre o programa $\mathrm{HuMed}^{12}$ e oferecem mais evidências do fato de que uma redução significativa nas exigências pré-médicas padrão não limita as habilidades dos alunos de assimilarem o conhecimento científico básico necessário para a promoção aos anos de estágio clínico. Igualmente, não limita seu sucesso durante os anos de estágio clínico, matérias eletivas, testes de habilidades clínicas, diligência em pesquisas ou seleção da residência.

Portanto, os alunos do HuMed não perderam nenhum ingrediente preparatório essencial ao adquirir uma educação universitária ampla em artes liberais no lugar das exigências científicas pré-médicas tradicionais e do MCTA. 


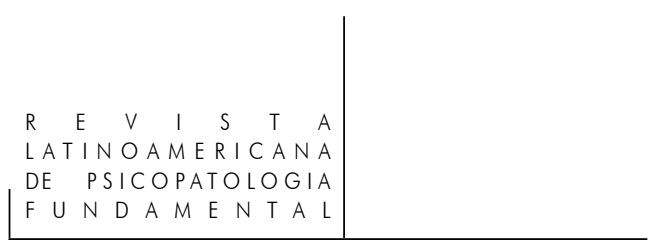

$\mathrm{Na}$ realidade, eles podem obter alguns ganhos advindos da educação diversa e enriquecedora em artes liberais que o relatório GPEP e outros anteciparam. Postulamos que esses ganhos podem incluir:

- Aumento das habilidades de comunicação e uma abordagem mais humanista junto ao paciente, conforme evidenciado pelo melhor desempenho dos alunos do HuMed em psiquiatria;

- maior interesse em buscar experiências mais amplas na faculdade de medicina, conforme evidenciado pela maior participação dos alunos do HuMed em bolsas e pesquisas; e

- ampliação do interesse em campos que fornecem mais conexões interpessoais entre paciente e médico, conforme evidenciado pela tendência dos alunos do HuMed a escolherem residências em cuidados primários e psiquiatria.

O sucesso do programa HuMed ao longo dos anos ampliou os critérios de admissão à Monte Sinai para todos os candidatos em potencial ao encorajar nossos comitês de admissão a olhar favoravelmente para graduações em ciências humanas e sociais. Enquanto a proporção nacional de matrículas de estudantes graduados em ciências humanas e sociais era inferior a $18 \%,{ }^{11}$ a proporção desses estudantes nas classes da Monte Sinai era de $25 \%$ sem os alunos do HuMed (43\% quando estes eram incluídos).

O grupo do HuMed apresenta pontuação inferior no USMLE Step 1, o que pode ser reflexo de sua formação não científica e dos desafios de ajustar-se a testes de múltipla escolha. Parece improvável que a diferença afete suas habilidades clínicas ou os impeça de manter posições de residência de alta qualidade.

Mais preocupante é a taxa significativamente maior de trancamento de matrícula entre os alunos do grupo HuMed. Isso pode indicar que um número bem pequeno de alunos enfrente dificuldades acadêmicas e efetue o trancamento antes de retornar à faculdade, ou esteja inseguro quanto à sua escolha de carreira e tenha sua incerteza combinada ao exigente currículo da faculdade de medicina. A Monte Sinai lida com essas preocupações de diversas maneiras. Em primeiro lugar, os padrões de admissão procuram identificar alunos de alto potencial acadêmico. Além disso, os alunos que frequentam o opcional SEP aprendem a estudar e a realizar testes em ciências exatas. Por fim, os candidatos à faculdade são fortemente encorajados a tirar pelo menos um ano sabático antes de matricular-se, o que lhes permite bastante tempo para refletir sobre sua escolha de carreira.

\section{Curso de verão de química orgânica e física}

Originalmente, a inclusão de um curso introdutório de química orgânica e física durante o curso mandatório de verão era necessária para atender as 
exigências do estado de Nova Iorque. Assim como o SEP, este curso deve proporcionar aos alunos HuMed uma valiosa preparação para o curso de trabalho na faculdade de medicina. Reconhecemos que essas disciplinas possuem valor educacional para futuros médicos e cientistas, mas sustentamos que os comitês de admissão dão demasiada importância a elas e que um tempo excessivo lhes é dedicado nas grades curriculares pré-médicas. Esse tempo poderia ser gasto em uma educação mais ampla em artes liberais e na ampliação do currículo científico para melhor atender as necessidades das revoluções deste século em biomedicina, tecnologia e políticas de saúde. ${ }^{6,7}$

\section{Limitações}

Nosso estudo possui diversas limitações. Primeiramente, o programa HuMed existe apenas na MonteSinai, e não sabemos se nossos resultados podem ser generalizados para outras instituições, regiões e currículos.

Em segundo lugar, não fomos capazes de controlar o GPA dos alunos do HuMed e dos demais alunos. Uma vez aceitos no programa HuMed, geralmente em seu último ano, os alunos precisam manter um GPA mínimo de apenas 3,5. Esse padrão mínimo lhes dá a liberdade de explorar cursos mais desafiadores academicamente e tira-lhes o fardo de ter o GPA como definidor de seu sucesso acadêmico. É improvável que eles irão se esforçar tanto quanto seus colegas do grupo pré-médico para tirar as maiores notas no GPA. Além disso, é improvável que o GPA do primeiro ano de um aluno isolado possa ser fidedignamente utilizado para comparar habilidades acadêmicas entre os dois grupos.

Em terceiro lugar, é difícil monitorar um grupo distinto de alunos ao longo de toda sua educação médica. Não é raro que alunos adiem sua matrícula por um ou dois anos e, uma vez matriculados, às vezes efetuem o trancamento por razões pessoais. É comum que os alunos acrescentem um ano dedicado ao trabalho escolar ou à pesquisa aos tradicionais quatro anos da faculdade de medicina. Quando esses alunos retornam à faculdade, ingressam em uma turma diferente. Às vezes o currículo estudado com sua nova classe é diferente daquele da classe original. Embora a imensa maioria tenha seguido o tradicional caminho dos quatro anos, as pequenas variações na composição da classe podem ter tido efeitos imprevisíveis nos resultados acadêmicos, seja para os alunos do HuMed, seja para os demais.

Por fim, nosso estudo não se ocupa da questão da existência ou não de diferenças substanciais na escolha de carreira e no desempenho profissional entre os alunos do HuMed e os alunos de escolha pré-médica. Quais alunos escolhem carreiras mais academicamente orientadas? Qual grupo tem maior probabilidade 
de incorporar serviços comunitários e sociais ao seu trabalho? Qual grupo tem maiores taxas de satisfação entre os pacientes? Estamos buscando responder a essas questões por meio de pesquisas em curso entre os alunos da Monte Sinai.

\section{Conclusões}

O programa HuMed da Universidade Monte Sinai foi projetado para determinar até que ponto o MCAT e os tradicionais cursos pré-médicos em química orgânica, física e cálculo são necessários para uma conclusão bem-sucedida da grade curricular da faculdade de medicina. Ele também foi criado para encorajar alunos interessados nos elementos humanistas da medicina a considerar a carreira médica. Muitos desses alunos relutam inicialmente em escolher a medicina por estarem inseguros quanto ao seu interesse em ciências exatas, preocupados com sua habilidade em atender às altas expectativas escolares dos comitês de admissão, ${ }^{15}$ ou por não terem vontade de dedicar o tempo e o esforço necessários para ir ao encontro das exigências padrão de admissão nas faculdades de medicina.

A admissão no programa HuMed permite a esses alunos seguirem uma educação diversa em artes liberais e engajar-se em uma grande variedade de experiências curriculares e extracurriculares. Em nossa experiência, os benefícios advindos da liberalização da educação pré-médica de modo que os alunos possam focar-se em ciências humanas e sociais são significativos. ${ }^{16}$ Programas similarmente estruturados poderiam permitir, ou até requerer aos alunos, o estudo de estatística, genética, bioquímica e biologia molecular com o fim de desenvolver um "conhecimento científico básico mais orientado para as moléculas e mais sofisticado cientificamente". ${ }^{6}$

Apelos recentes para repensar as exigências universitárias pré-médicas sugeriram a intensificação da preparação científica e uma maior incorporação das artes liberais, de modo que os alunos possam "explorar e crescer acadêmica e intelectualmente... e preparar-se para a cidadania em sociedade." ${ }^{, 7} \mathrm{O}$ tema comum é a necessidade de remover conteúdos "irrelevantes à prática médica, a seus pesquisadores e administradores" e que servem apenas como um mecanismo de seleção de alunos através de um verdadeiro "julgamento de fogo" ${ }^{6,7}$

Conforme os bem-sucedidos resultados acadêmicos dos alunos HuMed ilustram, está claro que aliviar os alunos do fardo das tradicionais exigências pré-médicas na universidade irá provê-los com a oportunidade de seguir múltiplos e mais diversos caminhos rumo ao sucesso na faculdade de medicina. ${ }^{16}$ 
Agradecimentos: Os autores agradecem Lauri Borwn e Miki Rifkin, PhD, por sua colaboração na coleta de dados, e Robert Fallar, MS, pelo seu inestimável papel na análise dos dados.

\section{Notas}

1. Beck, A.H. The Flexner Report and the standardization of American medical education. JAMA, n. 291, p. 2139-2140, 2004.

2. Flexner, A. Medical Education in the United States and Canada. New York, NY: Carnegie Foundation for the Advancement of Teaching, 1910.

3. Dalen, J.E.; Alpert, J.S. Premed requirements: the time for change is long overdue. Am J Med., n. 122, p. 104-106, 2009.

4. Project Panel on the General Professional Education of the Physician and College Preparation for Medicine. Physicians for the Twenty-First Century. Washington, DC: AAMC, 1984.

5. Kirch, D.G. A word for the president: "The gateway to being a doctor: Rethinking premedical education." AAMC Reporter, April 2008.

6. Dienstag, J.L. Relevance and rigor in premedical education. $N$ Engl J Med., n. 359, p. 221-224, 2008.

7. Emmanuel, E.J. Changing premed requirements and the medical curriculum. JAMA, n. 296, p. 1128-1131, 2006.

8. Kanter, S.L. Toward a sound philosophy of premedical education. Acad. Med., n. 83, p. 423-424, 2008.

9. Gross, J.P.; Mommaerts, C.D.; Earl, D.; DeVries, R.G. After a century of criticizing premedical education, are we missing the point? Acad Med., n. 83, p. 516-520, 2008.

10. Thomas, L. How to fix the premedical curriculum. $N$ Engl J Med., n. 298, p. 11801181, 1978.

11. Association of American Medical Colleges. MCAT and GPAs for applicants and matriculants to U.S. medical schools by primary undergraduate major, 2009. Disponível em: <www.aamc.org/data/facts/applicantmatriculant/table18-facts09 mcatgpabymaj1-wed.pdf>. Acesso em: 26 fev. 2010.

12. Rifkin, M.R.; Smith, K.D.; Stimmel, B.D.; Stagnaro-Green, A.; Kase, N.G. The Mount Sinai humanities and medicine program: an alternative pathway to medical school. Acad Med., n. 75 (10 suppl), p. S124-S126, 2000.

13. Korn, S.L.; Stagnaro-Green, A.; Rose, S. The dean's letter summary statement: Valung scholarship, leadership, and academic achievement. Acad Med., n. 76 (suppl), p. S30-S32, 2001.

Rev. Latinoam. Psicopat. Fund., São Paulo, v. 13, n. 4, p. 652-666, dezembro 2010 
14. Gunderman, R.B.; Kanter, S.L. "How to fix the premedical curriculum" revisited. Acad Med., n. 83, p. 1158-1161, 2008.

15. Lovecchio, K.; Dundes, L. Premed survival: Understanding the culling process in premedical undergraduate education. Acad Med., n. 77, p. 719-724, 2002.

16. Jauhar, S. From all walks of life - Nontraditional medical students and the future of medicine. N Engl J Med., n. 359, p. 224-227, 2008.

David Muller

Professor-associado do Departamento de Educação Médica e Medicina; diretor de Educação Médica e presidente do Departamento de Educação em Medicina da Faculdade de Medicina Monte Sinai da Universidade de Nova Iorque, em Nova Iorque.

Nathan Kase

Professor dos Departamentos de Ginecologia e Obstetrícia, de Ciência Reprodutiva e do Departamento de Medicina e diretor emérito da Faculdade de Medicina Monte Sinai da Universidade de Nova Iorque, em Nova Iorque.

Correspondências podem ser endereçadas a

Dr. Muller

One Gustave L. Levy Place, Box 1255

New York, NY, 10029

telefone (212) 241-8716

e-mail: david.muller@mssm.edu 